\title{
O BIOMA PAMPA NOS ANOS INICIAIS: Uma investigação com professores e nos livros didáticos do PNLD
}

\author{
Luiza Frigo Pinto ${ }^{1}$ \\ Bruna Ambros Baccin² \\ Edward Frederico Castro Pessano3
}

\section{RESUMO}

O presente trabalho trata-se de uma pesquisa realizada com professores dos anos iniciais do ensino fundamental, que investigou a abordagem do bioma Pampa em suas aulas. A metodologia deste estudo foi de cunho qualitativo, realizado em três escolas públicas estaduais do RS. Os dados foram coletados a partir de um questionário semiestruturado, e para a análise utilizou-se a Análise de Conteúdo e a Técnica de Nuvens de Palavras. Posteriormente, realizou-se um estudo sobre a abordagem do bioma Pampa nos livros didáticos, indicados no PNLD 2016 dos anos iniciais. Quanto à análise dos questionários, os resultados inferem que os professores realizam uma abordagem simplificada e pouco contextualizada sobre o bioma Pampa em suas aulas. As justificativas apresentadas nas respostas remetem ao fato desta temática não estar contemplada no plano de estudos das escolas. Com relação à análise realizada nos livros didáticos do PNLD 2016, observou-se a existência de várias coleções disponíveis para a escolha dos professores, porém apenas cinco coleções apresentaram a contextualização da temática bioma Pampa. Destaca-se ainda, a utilização de diferentes recursos metodológicos por parte dos professores, objetivando a melhoria dos processos de ensino. Neste sentido, acredita-se que discussões voltadas aos conteúdos relacionados ao bioma Pampa podem contribuir de maneira significativa para que os estudantes aprendam, ainda nos anos iniciais, a importância desses ecossistemas e desenvolvam atitudes voltadas para a preservação e manutenção da biodiversidade do Pampa.

Palavras-chave: Bioma Pampa. Anos iniciais. Professores. Livros didáticos.

\footnotetext{
1 Doutoranda em Educação em Ciências: Química da Vida e Saúde, Universidade Federal do Pampa, Uruguaiana, Rio Grande do Sul, Brasil. Orcid iD: https://orcid.org/0000-0002-94765949. E-mail: luiza.frigo@yahoo.com.br

2 Doutoranda em Educação em Ciências: Química da Vida e Saúde, Universidade Federal de Santa Maria, Santa Maria, Rio Grande do Sul, Brasil. Orcid iD: https://orcid.org/0000-00027017-9849. E-mail: brunabaccin@hotmail.com

3 Doutor em Educação em Ciências: Química da Vida e Saúde. Professor da Universidade Federal do Pampa, Uruguaiana, Rio Grande do Sul, Brasil. Orcid iD: https://orcid.org/00000002-6322-6416. E-mail: edwardpessano@unipampa.edu.br
} 


\title{
THE PAMPA BIOME IN ELEMENTARY SCHOOL: an investigation with teachers and PNLD textbooks
}

\begin{abstract}
The present work is a research carried out with teachers that work at the early years of elementary school, with the main goal of investigating how the Pampa biome is presented in their classes. The methodology followed in this study was a qualitative approach, carried out in three state public schools in the RS state. Data were collected through a semi-structured questionnaire, and Content Analysis and the Word Cloud Technique were used for the analysis. Subsequently, a study was carried out on the approach of the Pampa biome in the textbooks, indicated in the PNLD 2016 of the initial years. Regarding the analysis of the questionnaires, the results infer that the teachers perform a simplified and little contextualized approach about the Pampa biome in their classes. The justifications presented in the responses refer to the fact that this theme is not included in the schools' study plan. Regarding the analysis carried out in the PNLD 2016 textbooks, it was observed that there are several collections available for the choice of teachers, however only five collections presented the contextualization of the theme Pampa biome. It is also noteworthy the use of different methodological resources by teachers, aiming at improving teaching processes. In this sense, it is believed that discussions focused on the contents related to the Pampa biome can significantly contribute for students to learn, even in the early years, the importance of these ecosystems and develop attitudes aimed at the preservation and maintenance of the Pampa's biodiversity.
\end{abstract}

Keywords: Pampa Biome. Initial years. Teachers. Didatic books.

\section{EL ENFOQUE DE PAMPA BIOMA Y LOS LIBROS DE ENSEÑANZA: UMA MIRADA DE LOS MAESTROS EM LOS LOS PRIMEROS AÑOS DE EDUCACIÓN TERRESTRE EM RS, BRASIL}

\section{RESUMEN}

El objetivo del trabajo es estudiar la actividad de los docentes em loss primeros años de la escuela primaria y analizar su perspectiva del bioma Pampa en sus clases. Com base em unametodología cualitativa a través del análisis de contenido, entrevistas y la técnica de nube de palavras realizado em três escuelas selecionadas em RS Brasil, se realizó un estudio sobre el abordaje del bioma Pampa en los libros de texto, señalado en el PNLD 2016 Se econtró queos docentes realizan un abordaje simplificado y poco contextualizado sobre el bioma Pampa en sus clases; asimismo, se evidencia que este tema no está incluido en el plan de estudios de las escuelas y se observó que existen varias colecciones disponibles para la elección de los docentes. El trabajo discute em lo essencial que las discusiones enfocadas en los contenidos relacionados con el bioma pampeano pueden contribuir significativamente a que los estudiantes aprendan y desarrollen actitudes 
encaminadas a la preservación y mantenimiento de la biodiversidad de la Pampa em Brasil

Palabras clave: Pampa Biome. Años iniciales. Maestros. Libros didácticos.

\section{INTRODUÇÃO}

O ensino de Ciências nos anos iniciais pode estimular os estudantes a construírem os seus primeiros significados sobre o mundo, e assim, ampliarem os seus conhecimentos, sua cultura, e sua possibilidade de compreender e atuar na sociedade em que se encontram (VIECHENESKI; CARLETTO, 2013).

Nessa perspectiva, é tarefa da escola propiciar o acesso aos conhecimentos científicos, principalmente desde os primeiros anos da escolarização (OLIVEIRA et al., 2013), pois é o local privilegiado para o ensino de conteúdos conceituais, procedimentais e atitudinais (POZO; CRESPO, 2009). Desta forma, esses conteúdos poderão contribuir na compreensão de mundo, nas transformações que nele ocorrem e a partir dos conhecimentos científicos aprendidos, as crianças possam realizar as escolhas conscientes em seu cotidiano (MEDEIROS et al., 2011).

Segundo alguns autores (ROSA; PEREZ; DRUM, 2007) os professores dos anos iniciais do Ensino Fundamental apresentam dificuldades em proporcionar um ensino interdisciplinar e contextualizado, uma vez que sua formação inicial está voltada para a alfabetização e letramento, e também pelo fato de o curso de Pedagogia não responder diretamente às necessidades de formação de caráter científico.

Ainda, Santos (2007), Longhini (2008) e Moraes (2014) apontam que os professores dos anos iniciais apresentam um conhecimento limitado dos conteúdos do ensino de Ciências, especialmente devido à ausência de disciplinas científicas, como Biologia, Química e Física ao longo de sua formação inicial.

Assim sendo, as atividades relacionadas as temáticas ambientais podem não ser amplamente desenvolvidas na formação inicial desses professores, demandando assim, de um aprendizado que poderá ser 
encontrado em cursos de formação continuada, o qual exige tempo e disponibilidade.

Conforme as Diretrizes Curriculares Nacionais da Educação Ambiental, no planejamento dos currículos as escolas devem considerar a diversidade sociocultural dos estudantes, bem como de suas comunidades de vida e dos territórios em que situam as instituições educacionais (BRASIL, 2012). Na perspectiva de fortalecer o compromisso da população em relação à conservação da biodiversidade dos biomas, é necessário promover o conhecimento desta temática, tornando os atores sociais cientes e reflexivos sobre os benefícios diretos e indiretos gerados na conservação destes ecossistemas.

Nesse sentido, alguns trabalhos de pesquisa indicam que compreender como as populações percebem, veem, interagem e agregam valores, seus sentimentos e ideias de pertencimento, podem facilitar os processos de gestão e conservação, além de servir de subsídio à elaboração e desenvolvimento de programas de comunicação e Educação Ambiental (PEDRINI; COSTA; GHILARDI, 2010; BRESOLIN; ZAKRZEVSKI, 2016).

Nesse contexto, o desenvolvimento de temáticas ambientais relacionadas ao cotidiano dos estudantes, pode ser excelente alternativa para o desenvolvimento dos conteúdos programáticos com maiores significados aos aprendizes (PESSANO et al., 2013).

Assim, destaca-se, o estudo do bioma Pampa, um dos biomas brasileiros, que localiza-se no estado do Rio Grande do Sul, o qual apresenta uma enorme diversidade de espécies da fauna e flora, com características climáticas e condições de solo próprias, abrigando enorme biodiversidade (BENCKE; CHOMENKO; SANTANA, 2016). Contudo, a abordagem do bioma Pampa nos anos iniciais ainda é recente. Estudos de Correa (2008), Paris et al. (2016) e Castro (2018) possibilitaram um diagnóstico sobre esta abordagem, revelando que os estudantes desconhecem as características mais gerais com relação a este tema.

Considerando as particularidades apontadas acima, esta pesquisa tem por objetivo investigar a abordagem do bioma Pampa pelos professores 
dos anos iniciais. Assim sendo, surge a questão norteadora desta pesquisa: "Como o bioma Pampa vem sendo abordado pelos professores dos anos iniciais em suas aulas e de que forma o livro didático pode contribuir com o desenvolvimento desta temática?"

Considerando o livro didático como um dos recursos didáticos mais utilizados pelos professores no processo de ensino e aprendizagem na educação básica (BEZERRA; SUESS, 2013), foram analisados os livros do Programa Nacional do Livro Didático (PNLD), referente ao ano de 2016, a fim de verificar a abordagem do tema bioma Pampa neste importante recurso pedagógico.

\section{O bioma pampa como tema de investigação}

O Brasil possui uma diversa e variada vegetação que, conforme Coutinho (2016), proporciona uma grande diversidade de biomas, devido aos tipos de solos e relevos de cada região. Essa diversidade constituí variadas fitofisionomias, com enorme riqueza de espécies de plantas e animais, abrigando formações ecossistêmicas com características distintas, que originam os biomas brasileiros, sendo eles: Amazônia, Caatinga, Cerrado, Mata Atlântica, Pantanal e Pampa (IBGE, 2004).

Dentre os biomas brasileiros, está o bioma Pampa, o qual apresenta em sua totalidade uma área de aproximadamente $750 \mathrm{mil} \mathrm{km}$, compartilhada pelos países da Argentina, do Brasil e do Uruguai (MAZURANA; DIAS; LAUREANO, 2016; CHOMENKO, 2017).

No território brasileiro, o Pampa abrange a metade sul e região sudoeste do estado do Rio Grande do Sul, com uma área, aproximadamente, de $177.767 \mathrm{~km}^{2}$ (BRASIL, 2011), o que corresponde a $63 \%$ do território Gaúcho, fazendo com que o Pampa seja o único bioma cuja ocorrência torna-se restrita a apenas um estado brasileiro (Figura 01) (BOLDRINI et al., 2010; BENCKE; CHOMENKO; SANTANA, 2016). 
FIGURA 01 - Imagem da distribuição do bioma Pampa no RS

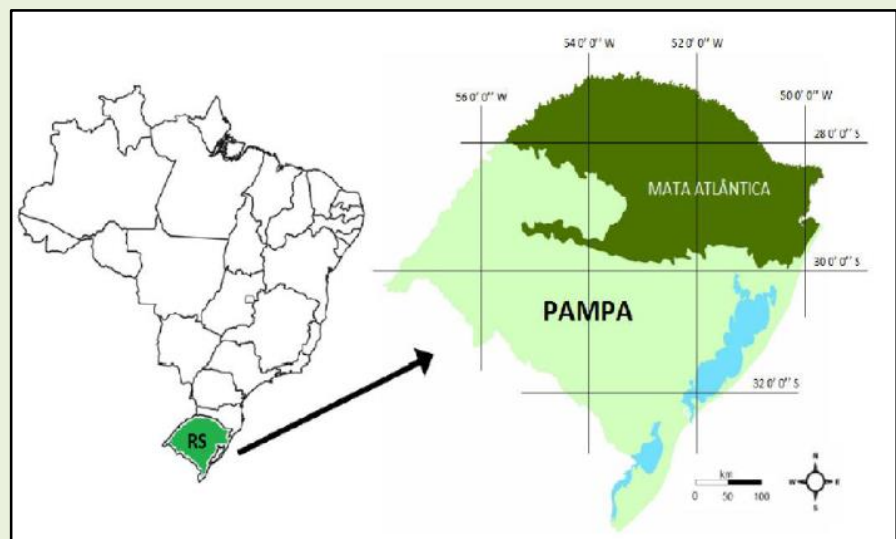

Fonte: [SANTOS; SILVA, 2011].

Conforme os autores Bencke, Chomenko, Sant'anna (2016, p. 17) o bioma Pampa "constitui a maior extensão de ecossistemas campestres de clima temperado do continente sul-americano", onde os campos nativos constituem a vegetação natural na paisagem deste bioma.

O bioma Pampa configura-se como o bioma de menor representatividade no Sistema Nacional de Unidades de Conservação, e conforme os dados do Instituto Chico Mendes de Conservação da Biodiversidade (ICMBIO) este apresenta apenas $0,4 \%$ da área continental brasileira protegida por unidades de conservação. Salienta-se, que de acordo com Bencke (2016) este bioma apresenta uma grande diversidade de espécies e de ecossistemas adaptados ao seu habitat, e raramente encontradas em outros biomas campestres do planeta.

Neste sentido, faz-se necessário propor estratégias de conservação voltadas ao Pampa, pois são áreas de grande importância, tanto pelas suas formas vegetais, animais, como pelos processos biológicos envolvidos, os quais precisam ser mantidos para o bom funcionamento dos processos ecossistêmicos e da própria sustentabilidade do bioma (BRACK, 2011; PARIS et al., 2016).

Ainda, conforme destacado na Base Nacional Comum Curricular (BRASIL, 2018, p.355) 
É importante também que os alunos percebam as relações com o ambiente e a ação dos seres humanos com o mundo que os cerca, refletindo sobre os significados dessas relações. Nesse período, o desenvolvimento da capacidade de observação e de compreensão dos componentes da paisagem contribui para a articulação do espaço vivido com o tempo vivido. O vivido é aqui considerado como espaço biográfico, que se relaciona com as experiências dos alunos em seus lugares de vivência.

Assim, entende-se que a abordagem de questões relacionadas com o cotidiano dos estudantes pode contribuir de forma significativa no desenvolvimento de ações voltadas para a preservação e conservação do ambiente natural em que vivem.

\section{METODOLOGIA}

Esta pesquisa configura-se como um estudo de caráter qualitativo, que de acordo com Minayo (2001) trabalha com o universo de significados, motivos, aspirações, crenças, valores e atitudes, a qual responde a questões muito particulares, com um nível de realidade que não pode ser quantificado.

Participaram da pesquisa dezenove (19) professores de três escolas públicas estaduais do Rio Grande do Sul. As escolas pesquisadas foram identificadas por letras, sendo a escola $\underline{A}$ situada na área urbana de Jaguari, a escola $\underline{B}$, na área rural da mesma cidade, e a escola $\underline{C}$ localiza-se na área urbana de Uruguaiana. Sendo que o município de Jaguari está localizado em uma região de transição entre os biomas Pampa e Mata Atlântica, já no município de Uruguaiana está situado exclusivamente no bioma Pampa.

Os professores responderam a um questionário semiestruturado, contendo sete questões. Desse modo, para expor as respostas dos professores, optou-se por identificá-los, neste estudo, como $\underline{\mathrm{Pl}}$ ao $\underline{\mathrm{P} 7}$ os professores da escola A, do $\underline{\mathrm{P} 8}$ ao $\underline{\mathrm{P} 12}$ da escola B e por fim, do $\underline{\mathrm{P} 13}$ ao $\underline{\mathrm{P} 19}$ os professores da escola C.

As questões foram agrupadas em quatro blocos, sendo o bloco 01 apresenta o perfil profissional geral dos entrevistados, o bloco 02 apresenta duas questões fechadas sobre os biomas, e no bloco 03 agrupou-se as três 
questões sobre a abordagem do bioma Pampa, e por fim, o bloco 04 sobre os materiais didáticos utilizados pelos professores, conforme o quadro(01) abaixo.

Quadro 01- Blocos de questões elaborados a partir do questionário

\section{Bloco 01}

1- Perfil profissional (tempo de magistério e gênero).

Bloco 02

2- Você já trabalhou com os Biomas Brasileiros com seus alunos? ( )Sim ( ) Não

3- E mais especificamente, você já trabalhou o bioma Pampa com seus alunos? () $\operatorname{Sim}$ ()Não

Bloco 03

4- Se já trabalhou o bioma Pampa com seus alunos, de que forma foi feito?

5- Se sua resposta foi negativa com o trabalho do bioma Pampa em sala de aula quais os aspectos que você apontaria para não ter trabalhado com seus alunos?

6- Você acredita que os estudantes ao final dos anos iniciais do ensino fundamental, apresentam noções sobre o Bioma Pampa, como uma unidade ecológica de caráter único com fauna e flora de características específicas? ( ) Sim ( ) Não

Justifique:

\section{Bloco 04}

7- Quais materiais didáticos você utiliza?

Fonte: [os autores].

Para análise das respostas dos professores, foi utilizada a metodologia de Análise de Conteúdo (BARDIN, 2016). Essa metodologia visa verificar hipóteses e/ou descobrir o que está por trás de cada conteúdo manifesto. O que está escrito, falado, mapeado, figurativamente desenhado e/ou simbolicamente explicitado sempre será o ponto de partida para a identificação do conteúdo manifesto, seja ele explícito e/ou latente, e será tratado de maneira aprofundada (MINAYO, 2001).

As diferentes fases da análise de conteúdo organizam-se em torno de três polos: 1) A pré-análise; 2) A exploração do material; e, por fim, 3) O tratamento dos resultados: a inferência e a interpretação (BARDIN, 2016).

A pré-análise é a fase em que se organiza o material a ser analisado, com o objetivo de torná-lo operacional, sistematizando as ideias iniciais. Nessa fase as respostas do questionário foram transcritas para o computador e foi realizada a leitura das respostas. 
A exploração do material constituiu a segunda fase, que consiste na definição de categorias, para as quais se utilizou algumas categorias préestabelecidas por Castro (2018), conforme apresentado no Quadro (02).

Quadro 02: Categorias de análise para as repostas de questões abertas

\begin{tabular}{|c|l|}
\hline CATEGORIA & \multicolumn{1}{|c|}{ DESCRIÇÃO } \\
\hline Abstenção & Quando não responde. \\
\hline Inadequada & $\begin{array}{l}\text { Quando responde sem relação com o } \\
\text { questionado. }\end{array}$ \\
\hline Parcialmente adequada & $\begin{array}{l}\text { Quando a resposta traz alguns elementos } \\
\text { que apresentam relação com o tema, mas } \\
\text { de forma mais ampla e confusa. }\end{array}$ \\
\hline Adequada & $\begin{array}{l}\text { Quando cita alguns elementos de acordo } \\
\text { com tema de forma apropriada e os } \\
\text { relaciona. }\end{array}$ \\
\hline
\end{tabular}

Fonte: [adaptada de CASTRO, 2018].

Destaca-se que, para a análise qualitativa buscando atender as categorias indicadas no quadro 2, buscou-se satisfazer as condições de exclusividade, homogeneidade, pertinência e representatividade dos dados.

$\mathrm{Na}$ terceira fase, realizou-se o tratamento dos resultados, inferência e interpretação das respostas. Nesta etapa ocorreram a condensação e o destaque das informações para análise, culminando nas interpretações inferenciais, sendo o momento da intuição, da análise reflexiva e crítica do material (BARDIN, 2016).

Para análise do bloco 04, foi utilizada a metodologia de Nuvens de Palavras, que consiste em usar tamanhos e fontes de letras diferentes de acordo com a frequência das ocorrências das palavras no texto analisado representando a ideia central do coletivo avaliado (PESSANO et al., 2015; PRAIS; ROSA, 2017). Esta forma mais visual pode facilitar a compreensão por parte de algumas pessoas e tem a facilidade de ser executada rapidamente através de páginas da internet, como o WordArt (www.wordArt.com).

Ainda com a finalidade de aprofundar as discussões realizadas neste estudo, realizou-se uma análise no PNLD 2016 para os anos iniciais, para a qual utilizou-se uma matriz de análise, conforme quadro (03) abaixo. 
Quadro 03 - Matriz para análise das coleções

\begin{tabular}{|c|l|}
\hline Categorias & Descrição \\
\hline Livro/Coleção/ Ano & $\begin{array}{l}\text { Quantidade de coleções ofertadas pelo PNLD } \\
\text { e Ano da elaboração do livro }\end{array}$ \\
\hline Conteúdos & $\begin{array}{l}\text { Conteúdos contemplados (presença ou não } \\
\text { dos biomas brasileiros e do Pampa) }\end{array}$ \\
\hline Opção por escola & Qual escola escolheu determinado livro \\
\hline Total de coleções & Número total de coleções no PNLD \\
\hline
\end{tabular}

Fonte: [os autores].

Portanto, o presente estudo foi desenvolvido em três etapas: 1) aplicação do questionário para os professores; 2) análise dos dados obtidos junto aos professores; 3) Análise do PNLD dos anos iniciais.

\section{RESULTADOS E DISCUSSÕES}

Na análise dos resultados do bloco 01, observa-se que os professores investigados possuem um tempo de exercício no magistério que varia de sete anos a quarenta e cinco anos. Sendo que da totalidade de dezenove (19) professores investigados, constatou-se que todos eram do gênero feminino.

Neste sentido, percebe-se uma predominância do gênero feminino nos anos iniciais, onde segundo Louro (2012), "[...] se o destino primordial da mulher era a maternidade, bastaria pensar que o magistério representava de certa forma, uma extensão da maternidade [...]" (LOURO, 2012, p. 450), sendo uma tarefa que ela já executava em seu lar, e por isso, estava preparada para cuidar das crianças (GONÇALVES; FARIA; REIS, 2016).

Com relação a análise do bloco 02, que agrupou duas questões propostas no questionário, elaborou-se a tabela 01 abaixo: 
Tabela 01 - Questões do Bloco 02

\begin{tabular}{cccccccc|c}
\hline & \multicolumn{3}{c}{ Escola A } & \multicolumn{2}{c|}{ Escola B } & Escola C & Total \\
\cline { 2 - 6 } & $\operatorname{Sim}$ & Não & $\operatorname{Sim}$ & Não & Sim & Não & \\
\hline $\begin{array}{c}\text { Você já } \\
\text { trabalhou biomas } \\
\text { brasileiros com } \\
\text { seus alunos? }\end{array}$ & 0 & 7 & 2 & 3 & 6 & 1 & 19 \\
\hline $\begin{array}{c}\text { E mais } \\
\text { especificamente, } \\
\text { você já trabalhou } \\
\text { o bioma Pampa } \\
\text { com seus alunos? }\end{array}$ & 0 & 7 & 5 & 0 & 6 & 1 & 19 \\
\hline
\end{tabular}

Fonte: [dados da pesquisa].

Os resultados revelam que na escola $A$, as professoras não trabalham a temática dos biomas brasileiros, enquanto na escola B, duas professoras relatam que trabalham os biomas brasileiros, e três responderam que não, porém quando perguntadas se abordam o bioma Pampa, todas responderam afirmativamente. A análise infere que, apesar de as professoras não trabalharem os biomas brasileiros, promovem atividades relacionadas às características dos ecossistemas locais, no qual a escola está inserida

Para a escola C, observa-se que seis professoras desenvolvem atividades relacionadas aos biomas brasileiros e também ao Pampa, sendo que apenas uma professora respondeu que não trabalha ambos os temas.

Ao examinar as respostas das duas questões apresentadas neste bloco, denota-se que a maioria das professoras das escolas B e C procuram elaborar atividades relacionadas a ambos os temas.

Neste sentido, Paris et al. (2016, p.120)

\begin{abstract}
"A conservação do Pampa é uma necessidade, já que as formas vegetais, animais e os processos biológicos desse sistema devem ser mantidos para as gerações futuras e para o funcionamento dos processos ecossistêmicos deste bioma".
\end{abstract}

Assim, é necessário que as crianças comecem a adquirir estes conhecimentos desde os anos iniciais, contribuindo para o reconhecimento 
dos ecossistemas, e assim possam interagir com o meio de forma a preserválo.

Na análise das questões do bloco 03, foram adaptadas as categorias estabelecidas por Castro (2018). Desta forma, em relação à análise da primeira questão: "E se já trabalhou o bioma Pampa com seus alunos, de que forma foi feito?" obteve-se a tabela (02) a seguir apresentado:

Tabela 02 - Análise da primeira questão do bloco 03

\begin{tabular}{cccc}
\hline & \multicolumn{3}{c}{ Número de ocorrências } \\
Categorias & Escola A & Escola B & Escola C \\
\hline Abstenção & 7 & 0 & 1 \\
\hline Inadequada & 0 & 0 & 0 \\
\hline $\begin{array}{c}\text { Parcialmente } \\
\text { Adequada }\end{array}$ & 0 & 0 & 0 \\
\hline Adequada & 0 & 5 & 6 \\
\hline
\end{tabular}

Fonte: [dados da pesquisa].

Quanto a análise da tabela (02), verificou-se que na escola A, todas as professoras investigadas não responderam à questão, por isso obteve-se um total de sete respostas na categoria "abstenção".

Já na escola B todas as respostas foram consideradas dentro da categoria "adequada", pois a partir da avaliação qualitativa, verifica-se que os investigados citaram alguns elementos de acordo com tema, de forma apropriada e os relacionaram, como pode ser exemplificado a partir das respostas abaixo:

P09- "Nas séries iniciais são trabalhadas as características de fauna e flora. Obs: como nosso município está localizado em área de transição são estudadas as características de Pampa e Mata Atlântica".

P10- "Foi trabalhado, porém não com essa nomenclatura. Os trabalhos realizados foram no sentido de valorização e preservação do meio ambiente (fauna e flora)".

Conforme as respostas, é possível observar que as professoras abordam algumas características do bioma e buscam contemplar ao menos 
algumas características pertinentes ao tema, como exposto no fragmento da frase "características de fauna e flora", o que revela preocupação e conhecimento sobre a temática. Entretanto, de acordo com Delizoicov e Slong (2011) nos anos iniciais priorizam-se os conhecimentos relativos à Língua Portuguesa e à Matemática, em detrimento do ensino das Ciências Naturais.

Na escola C, obteve-se uma resposta para a categoria "abstenção", e seis na categoria "adequada", sendo que na categoria "adequada", as professoras responderam que buscam desenvolver a temática em suas aulas. Como pode ser observado nos fragmentos de respostas abaixo:

P13- "Através de pesquisas realizadas pelos alunos, folhas com textos e imagens informativas".

P18- "Livro didático como apoio para mostrar aos alunos, pesquisa, debates, vídeos, construção de maquetes, só temos um livro do RS, mas que não aborda o Pampa".

Observa-se que diferentemente das escolas A e B, as professoras investigadas da escola $C$ procuram desenvolver de forma mais ampla as características do tema investigado, utilizando para o ensino algumas ferramentas didáticas, como vídeos, leitura de textos, maquetes, mapas e livros didáticos, buscando assim, contextualizar com o cotidiano dos estudantes.

Conforme o Referencial Curricular Gaúcho (RIO GRANDE DO SUL, 2018) o conhecimento deve estar contextualizado com a realidade individual, local e social do estudante, sendo que o objetivo da Ciência é que este consiga compreender e interpretar o mundo, possibilitando sua interferência no ambiente que o cerca, transformando-o em um ambiente mais sustentável. Isto vai ao encontro do manifestado por Pessano e colaboradores (2015), onde a contextualização dos conteúdos proporciona maiores significados à aprendizagem dos estudantes, despertando o interesse dos alunos para os conteúdos abordados.

A segunda questão do bloco 03, "Se sua resposta foi negativa com o trabalho do bioma Pampa em sala de aula, quais os aspectos que você 
apontaria para não ter trabalhado com seus alunos?" obteve-se a tabela 03 a seguir:

Tabela 03 - Análise da segunda questão do bloco 03

\begin{tabular}{cccc}
\hline & \multicolumn{3}{c}{ Número de ocorrências } \\
Categorias & Escola A & Escola B & Escola C \\
\hline Abstenção & 0 & 5 & 6 \\
\hline Inadequada & 0 & 0 & 0 \\
\hline $\begin{array}{c}\text { Parcialmente } \\
\text { Adequada }\end{array}$ & 2 & 0 & 0 \\
\hline Adequada & 5 & 0 & 1 \\
\hline
\end{tabular}

Fonte: [dados da pesquisa].

Analisando as respostas, podemos perceber que a escola A teve duas respostas na categoria "parcialmente adequada", como podem ser observadas nas respostas abaixo:

P04- "Trabalhamos o relevo no $5^{\circ}$ ano (RS), com algumas características não aprofundamos".

P05- "No $5^{\circ}$ ano trabalha-se só o relevo".

Pode-se observar que as professoras mencionam desenvolver 0 conteúdo relativo ao relevo do Rio Grande do Sul, mas não especificam abordar características do Pampa. Assim, pode-se inferir que talvez elas não utilizem desta nomenclatura quando se referem as características do Pampa, tratando-o apenas de forma geral.

Analisando ainda as respostas obtidas na escola A, obteve-se cinco respostas agrupadas na categoria "adequada", que pode ser observado através das respostas abaixo citadas:

P3 - "Por não estar contemplado no nosso plano de trabalho pois seguimos conteúdos específicos".

P7 - "Não consta nos planos de estudos das turmas com as quais trabalhei". 
Destaca-se que as professoras responderam à questão justificando que não trabalham com o bioma Pampa, pois este não está contemplado em seus planos de estudos, documentos estes que regem a sequência de conteúdos que devem ser abordados durante o ano letivo, para cada ano em específico.

As respostas obtidas pelas professoras da escola B foram agrupadas na categoria "abstenção", pois não responderam ao questionamento. Nas respostas da escola $C$, observa-se que seis respostas foram agrupadas na categoria "abstenção" e uma na categoria "adequada", conforme a resposta abaixo:

P17 - "Muitas vezes nem o próprio professor tem o conhecimento do assunto".

Neste sentido, é possível inferir que essa resposta está relacionada a formação inicial do professor dos anos iniciais, que conforme Batista e Lima (2018) durante a formação deste professor é dada pouca atenção ao ensino de Ciências, ocasionando dificuldades e lacunas na formação científica, entre outras questões. Ainda Flaviano (2017), a formação dos professores dos anos iniciais não os prepara de forma satisfatória para $\circ$ ensino teórico e prático do currículo de Ciências.

Neste sentido, Paris e colaboradores (2016, p. 118) corroboram com este resultado, quando explicam que "Provavelmente, nas escolas da região, não acontece o estudo sobre as espécies vegetais e animais do bioma Pampa", e quando abordam esses conteúdos, limitam-se ao conteúdo encontrado nos livros didáticos, que em muitos casos, apresentam nomenclaturas diferentes para o tema investigado.

$\mathrm{Na}$ análise da terceira questão do bloco 03, que questiona: "você acredita que os estudantes ao final dos anos iniciais do ensino fundamental, apresentam noções sobre o Bioma Pampa, como uma unidade ecológica de caráter único com fauna e flora de características específicas? ( ) Sim ( ) Não. Justifique:". Assim, obteve-se a tabela (04) abaixo. 
Tabela 04 - Análise da terceira questão do bloco 03

\begin{tabular}{|c|c|c|c|c|c|c|}
\hline \multirow[b]{3}{*}{ CATEGORIAS } & \multicolumn{6}{|c|}{ Número de ocorrências } \\
\hline & \multicolumn{2}{|c|}{ Escola A } & \multicolumn{2}{|c|}{ Escola B } & \multicolumn{2}{|c|}{ Escola C } \\
\hline & Sim $=2$ & Não $=5$ & Sim $=3$ & Não= 2 & $\operatorname{sim}=2$ & $N \tilde{a} 0=5$ \\
\hline Abstenção & \multicolumn{2}{|r|}{0} & \multicolumn{2}{|c|}{0} & \multicolumn{2}{|c|}{1} \\
\hline Inadequada & \multicolumn{2}{|r|}{0} & \multicolumn{2}{|c|}{0} & \multicolumn{2}{|c|}{1} \\
\hline $\begin{array}{l}\text { Parcialmente } \\
\text { Adequada }\end{array}$ & \multicolumn{2}{|r|}{2} & \multicolumn{2}{|c|}{3} & \multicolumn{2}{|c|}{0} \\
\hline Adequada & \multicolumn{2}{|r|}{5} & \multicolumn{2}{|c|}{2} & \multicolumn{2}{|c|}{5} \\
\hline
\end{tabular}

Fonte: dados da pesquisa.

Portanto, quando observada às respostas obtidas na escola $\mathrm{A}$, percebe-se que duas professoras responderam que sim, mas quando solicitadas a justificar suas respostas, estas, disseram que é conteúdo trabalhado no $5^{\circ}$ ano. Como pode ser observado nas repostas a seguir relatadas:

P06 - "É conteúdo trabalhado em outros anos ( $5^{\circ}$ ano)".

P07- "É trabalhado no $5^{\circ}$ ano e retomando nos anos finais".

Contudo, ao observar as informações obtidas, estas duas professoras nunca desenvolveram atividades no $5^{\circ}$ ano, fato este, que fez com que as duas respostas fossem agrupadas na categoria "parcialmente adequada", pois estas professoras não trabalham com este ano.

$\mathrm{Na}$ análise das respostas da escola B, obteve-se três respostas na categoria "parcialmente adequada" e duas na categoria "adequada". Ao observar as respostas inseridas na categoria "parcialmente adequada" percebe-se a utilização de uma explicação vaga e ampla, como pode ser analisado nas respostas abaixo mencionadas:

P10- "Acredito que sim, pois os trabalhos ajudam na conscientização da importância da flora e fauna para a sobrevivência das gerações futuras".

P11- "Algumas noções sim, porque sempre é trabalhado, dentro das temáticas do meio ambiente, as características da região, bem como a importância e o reconhecimento dessas áreas para a nossa vida e para as gerações futuras". 
Nesse sentido, justifica-se o agrupamento destas respostas nesta categoria, pois as professoras relatam que trabalham de forma geral as características da região e mencionam a importância deste aprendizado para os estudantes, mas não trouxeram no contexto das respostas a temática pesquisada, e também, não deixam claro a respeito do entendimento do assunto pelos estudantes.

$\mathrm{Na}$ categoria "adequada" foram agrupadas duas respostas, casualmente idênticas, onde as professoras responderam de forma sucinta o porquê acreditam que os estudantes não apresentam noções a respeito do bioma Pampa, como pode ser verificado nas respostas abaixo.

P08 e P12- "Não. Esses conceitos não são trabalhados nas séries iniciais, e sim nas séries finais do ensino fundamental".

Partindo para a análise das respostas obtidas na escola C, obteve-se o agrupamento das respostas em três categorias, sendo uma resposta na categoria "abstenção", uma na categoria "inadequada" e cinco respostas na categoria "adequada".

Na análise da categoria "inadequada" a professora citou motivos para não desenvolver atividades relacionadas ao bioma Pampa, e sem relação ao que foi questionado, como pode ser observado abaixo.

P16 - "São vários. Uma lista imensa de conteúdos, muitas vezes irrelevantes. A impossibilidade de exercitar a prática por falta de espaço, material, transporte, interesse. No caso do interesse, a maioria das vezes, falta pelos motivos anteriores".

Quando analisadas as respostas inseridas na categoria "adequada", as professoras procuraram responder de forma objetiva o porquê de suas respostas serem afirmativas ou não. Sendo possível analisar nas respostas trazidas abaixo:

P14 - "Não, porque o livro didático é bastante resumido e não temos outro material para utilizar". 
P18 - "Sim. Quando questionados, os alunos demostram conhecer áreas importantes como o Parque do Espinilho, o Cerro do Jarau e contam como é a vegetação da nossa região".

É necessário observar a resposta da professora P18, que revela algumas informações importantes para a pesquisa, onde ela relata que os estudantes reconhecem como importantes os locais relacionados ao bioma Pampa.

A professora menciona que os estudantes citam o Parque do Espinilho, o qual fica situado no município de Barra do Quaraí, no extremo oeste do RS, junto à fronteira com a República Oriental do Uruguai e ao longo do Rio Uruguai no limite com a Argentina (Secretaria Estadual do Meio Ambiente, 2007).

Já o Cerro do Jarau, citado na resposta acima, localiza-se no município de Quaraí, ocupando 5,5\% do território municipal, e corresponde a $0,11 \%$ do bioma Pampa. Abrange ecossistemas representativos do bioma Pampa, e conforme a Secretaria do Meio Ambiente e Infraestrutura, o Cerro do Jarau é composto por "[...] campos, campos rupestres, matas ciliares, capões de mata, parque de inhanduvá e cursos d'água, associados às espécies de fauna características da região" (SEMA, s/a).

As regiões citadas pela professora P18 são importantes para a manutenção da biodiversidade do Pampa, pois se localizam em áreas remanescentes deste bioma, com uma grande importância ecológica, fazendo-se necessária a preservação destes locais, pois abrigam ecossistemas únicos e exclusivos em todo o País. Portanto, as atividades desenvolvidas nas escolas são fundamentais para que 0 estudante reconheça a importância desses lugares, compreendendo a necessidade de preservação e manutenção dos ecossistemas, a fim de garantir a sobrevivência de espécies animais e vegetais.

A respeito da questão do bloco 04 "Quais materiais didáticos você utiliza?" foi elaborada uma nuvem de palavras ou word clouds, que utiliza técnicas de processamento de linguagem por meio de ferramentas on-line, para a visualização quantificada do número de ocorrências das palavras 
nos textos. As nuvens de palavras são reveladoras, pois apresentam de maneira resumida a visão geral dos conceitos e termos investigados (LOUSAN, 2014). Dessa maneira, obteve-se ao final da organização das palavras, a figura (02) a seguir.

Figura 02: Nuvem de palavras

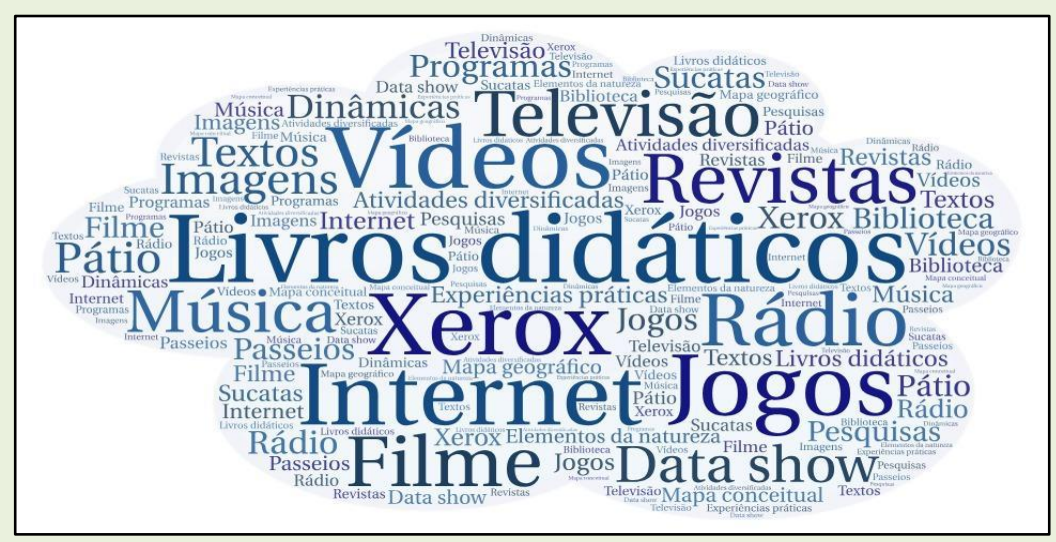

Fonte: [dados da pesquisa].

Ao analisar a nuvem de palavras foi possível observar que algumas

palavras se destacaram em relação às demais, ou seja, foram as mais citadas pelas professoras, como, "livros didáticos", "xerox", "vídeos", "internet" e "jogos". Durante a elaboração da nuvem de palavras verificouse que as professoras citaram sempre a utilização dos livros didáticos como recurso, mostrando que o livro ainda é a principal fonte de informações por parte dos professores.

Tratando-se da relação entre o uso do livro didático e o professor, os dados sugerem que há uma relação efetivamente estreita, sendo notável o grande número de professores que aderem ou identificam a sua proposta de trabalho com a proposta pedagógica apresentada pelo livro didático.

Segundo os autores Horikawa e Jardilino (2010), os autores dos livros didáticos prezam por uma organização de trabalho e do tempo escolar, possibilitando que o professor encontre de forma organizada a sequência de conteúdos a ser desenvolvida, facilitando o trabalho do professor.

Contudo, segundo os mesmos autores, isso pode limitar a busca por outras informações, pois, o livro passa a oferecer os conteúdos e conceitos 
de forma pronta, podendo causar acomodação por parte do professor, o qual deixa de elaborar e buscar a articulação entre os conhecimentos, de forma reflexiva, criativa e individual (HORIKAWA; JARDILINO, 2010).

Desta forma, o trabalho buscou avaliar o livro didático, por ser um dos principais recursos utilizados e a relação de abordagem com a temática proposta em relação ao bioma Pampa, buscando qualificar as análises efetuadas.

\section{Análise dos Livros didáticos dos Anos Iniciais - PNLD 2016}

Os anos iniciais do ensino fundamental incluem o período onde se inicia o desenvolvimento do conhecimento formal. Desta maneira, os professores podem contar com diferentes materiais didáticos disponibilizados pelas escolas para auxiliar no desenvolvimento dos conteúdos.

As respostas dos professores obtidas através da aplicação do questionário revelaram que a utilização dos livros didáticos é a principal forma de acesso as informações, portanto, faz-se necessário investigar se a temática do bioma Pampa está contemplada nos livros didáticos dos anos iniciais.

Para Bittencourt (2004), o livro didático é fundamental para a escolarização, pois provoca debates na escola, entre os alunos e os educadores, sendo momentos enriquecedores na formação dos estudantes, pois são espaços de conhecimentos compartilhados.

Assim, optou-se por analisar os livros do PNLD 2016, pois neste documento encontram-se todas as coleções de livros didáticos disponibilizados pelo Ministério da Educação. De acordo com o Fundo Nacional de Desenvolvimento da Educação (FNDE), o PNLD é o mais antigo dos programas voltados à distribuição de obras didáticas, atendendo estudantes da rede brasileira pública de ensino (BRASIL, 2001).

No PNLD 2016 existem três guias de escolha para os anos iniciais, sendo o primeiro guia voltado para as escolas públicas rurais, o segundo guia é direcionado para as Ciências Humanas e da Natureza e contempla os Livros Regionais, e por último, o terceiro guia, para Ciências: ensino fundamental 
anos iniciais. De acordo com os critérios de análise, foram investigados todos os guias, e dentro destes foram selecionados apenas os que contemplavam a temática de interesse. A partir da pesquisa realizada, foi elaborado um quadro para apresentar os resultados encontrados, conforme quadro (04).

Quadro 04 - Apresentação dos resultados da análise do PNLD

\begin{tabular}{|c|c|c|c|c|}
\hline Categorias PNLD & Livro/Coleção/Ano & Conteúdos & $\begin{array}{l}\text { Opção por } \\
\text { escola }\end{array}$ & $\begin{array}{l}\text { Total de } \\
\text { coleções }\end{array}$ \\
\hline $\begin{array}{l}\text { PNLD Campo } 2016 \\
\text { Educação no } \\
\text { Campo } \\
\text { Ensino } \\
\text { Fundamental e } \\
\text { Anos Iniciais }\end{array}$ & $\begin{array}{c}\text { Coleção Campo } \\
\text { Aberto - } 5^{\circ} \text { ano }\end{array}$ & $\begin{array}{l}\text { Cap. 6: } \\
\text { Paisagens, } \\
\text { biomas e } \\
\text { ecossistemas } \\
\text { brasileiros. }\end{array}$ & $\begin{array}{c}\text { Não } \\
\text { escolhido }\end{array}$ & 24 \\
\hline $\begin{array}{c}\text { PNLD 2016: } \\
\text { Ciências Humanas } \\
\text { e da Natureza } \\
\text { (CHN) } \\
\text { Livros Regionais: } \\
\text { ensino } \\
\text { fundamental anos } \\
\text { iniciais } \\
\end{array}$ & $\begin{array}{c}\text { Ligados.com } \\
\text { ciências humanas } \\
\text { e da natureza - } 5^{\circ} \\
\text { ano }\end{array}$ & $\begin{array}{l}\text { Unidade 2: } \\
\text { Biomas } \\
\text { brasileiros }\end{array}$ & $\begin{array}{c}\text { Escolhido } \\
\text { pela escola } \\
\text { A e C }\end{array}$ & 29 \\
\hline \multirow{3}{*}{$\begin{array}{l}\text { PNLD 2016: } \\
\text { Ciências: ensino } \\
\text { fundamental anos } \\
\text { iniciais. }\end{array}$} & $\begin{array}{l}\text { Aprender Juntos - } \\
\text { Ciências - } 5^{\circ} \text { ano }\end{array}$ & $\begin{array}{l}\text { Unidade 1- } \\
\text { Conhecendo } \\
\text { o Brasil: } \\
\text { Biomas } \\
\text { brasileiros; } \\
\text { Ambiente e } \\
\text { atividade } \\
\text { agrícola; }\end{array}$ & $\begin{array}{c}\text { Não } \\
\text { escolhido }\end{array}$ & \multirow[t]{3}{*}{13} \\
\hline & $\begin{array}{l}\text { Ligados.com } \\
\text { Ciências - } 4^{\circ} \text { ano }\end{array}$ & $\begin{array}{l}\text { Unidade 8 - } \\
\text { Biomas } \\
\text { brasileiros: } \\
\text { Biomas do } \\
\text { Brasil; } \\
\text { Amazônia; } \\
\text { Cerrado; } \\
\text { Mata } \\
\text { Atlântica; } \\
\text { Caatinga; } \\
\text { Pantanal; } \\
\text { Pampa. }\end{array}$ & $\begin{array}{c}\text { Escolhido } \\
\text { pelas } \\
\text { escolas A e } \\
\text { C }\end{array}$ & \\
\hline & $\begin{array}{c}\text { Projeto Buriti - } \\
\text { Ciências - } 5^{\circ} \text { ano }\end{array}$ & $\begin{array}{l}\text { Unidade 5 - } \\
\text { Biomas } \\
\text { brasileiros: } \\
\text { Principais } \\
\text { biomas } \\
\text { brasileiros; } \\
\text { Floresta } \\
\text { Amazônica; } \\
\text { Mata }\end{array}$ & $\begin{array}{c}\text { Não } \\
\text { escolhido. }\end{array}$ & \\
\hline
\end{tabular}




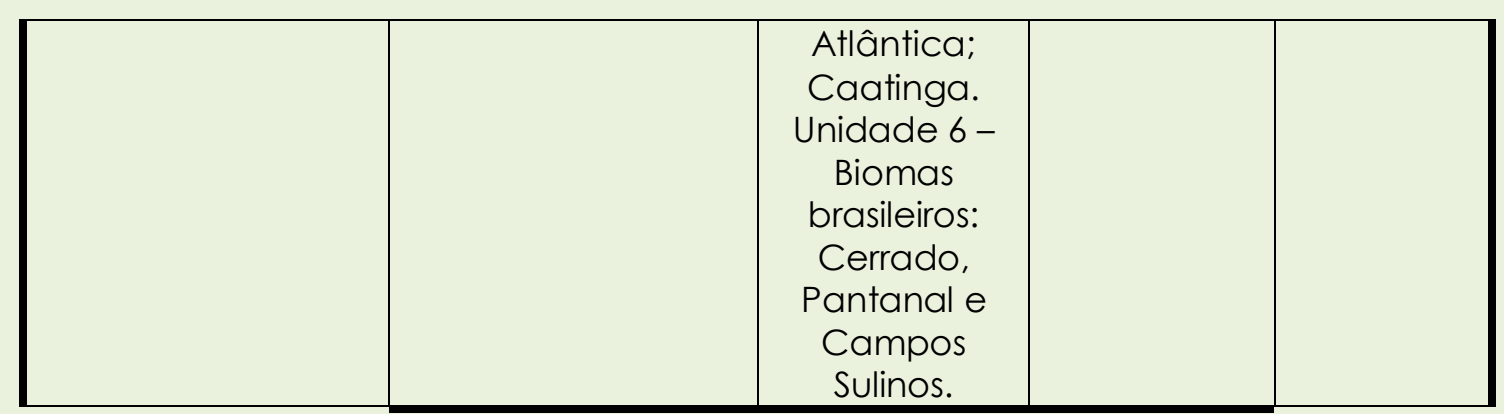

Fonte: [dados da pesquisa].

Durante a análise do primeiro guia "Educação no Campo: Ensino Fundamental e Anos Iniciais", estas coleções estão voltadas para as escolas inseridas em contexto rural. De acordo com o exposto no Quadro (04) O guia disponibiliza um total de vinte e quatro coleções para a escolha dos professores. Analisando a categoria "Livro/Coleção/Ano" foi identificado a "Coleção Campo aberto", direcionada ao $5^{a}$ ano dos anos iniciais. Com relação a categoria "Conteúdos", observa-se a disponibilidade do Capítulo 6: Paisagens, biomas e ecossistemas brasileiros. A categoria "Opção por escola" revela que esta coleção não foi escolhida por nenhuma escola investigada.

Embora a temática de interesse esteja disponível nesta coleção, esta não foi escolhida pela escola B, que é a única escola inserida no contexto rural. Tal afirmação pode ser feita com base no relatório de distribuição dos Livros Didáticos por escola, no Sistema do Material Didático (SIMAD).

De acordo com o PNLD Campo (BRASIL, 2015a), o livro didático precisa estar articulado para uma prática transformadora da escola em si e para a compreensão do que se produz para além da escola, e ainda conforme o PNLD "Um primeiro aspecto a considerar diz respeito à forma como o Campo e seus Sujeitos se fazem presentes em um livro didático" (BRASIL, 2015a, p. 13-14), sendo necessário relacionar as questões do cotidiano dos estudantes aos conhecimentos científicos estudados.

Na análise do segundo guia disponível intitulado "Ciências Humanas e da Natureza (CHN)/Livros Regionais: ensino fundamental anos iniciais" disponibiliza um total de vinte e nove coleções para a escolha dos professores conforme quadro (04). Em análise a categoria 
"Livro/Coleção/Ano" apresenta uma apenas o livro "Ligados.com ciências humanas e da natureza", direcionado para o $5^{\circ}$ ano.

Para a análise referente a categoria "conteúdos" tem-se a "Unidade 2: Biomas brasileiros" que contempla a temática investigada. E conforme a categoria "Opção por escola" e de acordo com o relatório de distribuição dos Livros Didáticos, as escolas A e C escolheram este livro para $O$ desenvolvimento dos conteúdos de Ciências humanas e da Natureza durante suas aulas.

Conforme pode ser observado, o guia "Ciências Humanas e da Natureza/Livros Regionais: ensino fundamental anos iniciais", apresenta os conteúdos relacionados ao tema investigado. E consta que a escola $A$ escolheu este livro, ou seja, a escola disponibiliza do material que contempla os biomas brasileiros, contudo, com base nas respostas obtidas através dos questionários, as professoras optam por não desenvolver o conteúdo bioma Pampa, pois levam em consideração os planos de estudos da escola, nos quais a temática não está contemplada.

Com base nas respostas das professoras da escola $C$, que possuem o livro didático relacionado a temática, estas demonstram desenvolver as questões relacionadas a temática investigada.

No que se refere aos livros regionais considera-se que estes são muito importantes no desenvolvimento dos conteúdos do bioma Pampa, pois são responsáveis pela contextualização das questões regionais e locais, e das características específicas de uma determinada região, e de acordo com o PNLD "registram a experiência de grupos que se identificam por fronteiras espaciais e socioculturais, seja na dimensão de uma cidade, um estado ou uma região do Brasil e que são utilizados em situação didática no ensino [...]" (BRASIL, 2015b, p. 331).

Quanto à análise do terceiro guia "Ciências: ensino fundamental anos iniciais" conforme exposto no Quadro (04) na categoria "Livro/Coleção/Ano" foram identificadas três coleções, de um total de treze coleções que estão disponíveis. A primeira coleção tem como título "Aprender Juntos - Ciências" e na análise da categoria "conteúdos" têm a 
Unidade 1 - Conhecendo o Brasil: Biomas brasileiros; Ambiente e atividade agrícola, voltado para o $5^{\circ}$ ano, mas com relação a categoria "Opção por escola", observa-se que esse material não foi escolhido por nenhuma escola investigada.

Na análise da segunda coleção Ligados.com Ciências, direcionado para $\bigcirc 4^{\circ}$ ano, e com relação a análise da categoria "conteúdos" disponibiliza-se a "Unidade 8 - Biomas brasileiros: Biomas do Brasil; Amazônia; Cerrado; Mata Atlântica; Caatinga; Pantanal; Pampa", e de acordo com a categoria "Opção por escola" o material foi selecionado pelas escolas A e C.

Esse é um dado que vem contribuir para as discussões anteriores, pois as professoras das escolas $\mathrm{A}$ e C disponibilizam dos mesmos materiais para desenvolver a temática pesquisada, voltados para $\circ 4^{\circ}$ e $5^{\circ}$ ano, porém como destacado anteriormente apenas à escola $C$ desenvolve a temática. No entanto, o motivo apontado pelas professoras da escola A é que esta é uma temática que não está contemplada em seus planos de estudos.

Dentro deste mesmo guia, tem-se a terceira coleção analisada Projeto Buriti - Ciências para o $5^{\circ}$ ano, e na análise da categoria "conteúdos", temse duas unidades sobre a temática investigada, a "Unidade 5 - Biomas brasileiros: Principais biomas brasileiros; Floresta Amazônica; Mata Atlântica; Caatinga" e a "Unidade 6 - Biomas brasileiros: Cerrado, Pantanal e Campos Sulinos". Com relação a categoria "Opção por escola" este livro não foi escolhido por nenhuma escola investigada.

Entretanto, destaca-se que este livro faz uma distinção entre os biomas, classificando-os como principais e demais biomas, colocando o Pampa como um bioma secundário. No entanto, de acordo com Bencke (2016) as pesquisas científicas indicam que o Pampa apresenta 2150 espécies de plantas que compõem uma diversidade florística raramente encontrada em outros biomas campestres do planeta.

Assim sendo, destaca-se que a valorização do Pampa e sua abordagem em sala de aula é importante para a preservação das espécies da flora e fauna, pois atribuem consideráveis estimativas a sua 
biodiversidade, ainda não conhecida completamente pela ciência (SANTOS, 2015; CHOMENKO, 2006).

Ainda, é possível destacar que os autores do livro referem-se ao bioma Pampa utilizando o termo Campos Sulinos, onde associam os campos do bioma Pampa à vegetação campestre existente no bioma Mata Atlântica, porém como já mencionado o Pampa é um bioma exclusivo do Rio Grande do Sul, e os Campos Sulinos formam uma única unidade ecológica composta por três regiões do Sul do Brasil, Rio Grande do Sul (RS), Santa Catariana (SC) e Paraná (PR) (OVERBECK et al., 2015).

No contexto da análise do PNLD constatou-se a existência de cinco coleções de um total de sessenta e seis disponibilizadas para a livre escolha do professor, e como foi possível verificar, apenas duas escolas escolheram os livros didáticos que atribuíam conteúdos a temática investigada. Sendo possivel constatar que isto não significa que o professor irá desenvolver tais conteúdos, pois a abordagem fica ao seu critério, e também de acordo com a sequência planejada em seus planos de estudo.

\section{CONSIDERAÇÕES FINAIS}

A partir do objetivo deste trabalho, de investigar a abordagem do bioma Pampa pelos professores dos anos iniciais, os dados apontam que esta temática não é amplamente desenvolvida pelos professores dos anos iniciais das escolas investigadas. Sendo que o principal motivo apontado é que esta é uma temática que não está contemplada nos planos de estudos destas escolas, pois primam por seguir a sequência apontada pelo referido documento.

Destaca-se que, quando analisadas as escolas de forma individual, observa-se que a escola A, situada na área urbana de Jaguari, é a que menos aborda a temática investigada, onde as respostas revelam que os professores trabalham apenas questões do relevo do RS, mas de forma geral, sem relacionar com o Pampa.

$\mathrm{Na}$ escola $\mathrm{B}$, as respostas revelaram que as professoras procuram desenvolver atividades relacionadas ao bioma Pampa, embora utilizem 
outra nomenclatura não citada nas respostas, e conforme mencionado anteriormente esta escola está inserida em uma área rural, tornando fundamental o desenvolvimento de atividades relacionadas ao contexto em que os estudantes vivem.

Em relação às respostas obtidas na escola $C$, a qual se localiza na área urbana de Uruguaiana, é possível observar um maior desenvolvimento da temática investigada, quando em comparação com as demais escolas envolvidas na pesquisa.

De acordo com a análise realizada no PNLD 2016 foi possível constatar a existência de cinco coleções que abordam a temática investigada e sugerem esta abordagem em sala de aula, mas a escolha ou não das coleções que apresentam a temática bioma Pampa, fica a critério do professor, uma vez que ele segue os seus planos de estudo.

Como limitações deste estudo, destaca-se a dificuldade do contato com algumas professoras, e o fato de ser um questionário semiestruturado, o que pode ter suprimido informações mais detalhadas, as quais poderiam permitir resultados mais aprofundados, contribuindo com as discussões realizadas neste estudo. E também, a formulação de alguma pergunta pode não ter sido compreendida pelos participantes, influenciando nos resultados encontrados.

O presente trabalho pode contribuir com a pesquisa educacional, por demonstrar a realidade do ensino em uma determinada região do país, em relação à forma de abordagem de um importante bioma brasileiro, podendo estimular que novas investigações ocorram em todo o país e favoreça a interlocução dos processos educacionais entre o meio ambiente, a escola, colaborando na formação dos indivíduos.

Por fim, destaca-se que mesmo que de forma superficial, a abordagem dos conteúdos relacionados ao bioma Pampa permeia a aprendizagem dos estudantes dos anos iniciais. Embora, seja necessário que os professores desenvolvam estratégias que facilitem aos estudantes contextualizar os conteúdos científicos com seu cotidiano, neste caso, o bioma Pampa, uma vez que estão nele inseridos. 
Agradecimentos

A CAPES, CNPQ pelo auxílio financeiro.

\section{REFERÊNCIAS}

BARDIN, L. Análise de Conteúdo. $3^{a}$ reimp. São Paulo: ed. 70, 2016.

BATISTA, E. R. M.; LIMA, T. M. Formação de professores no curso de pedagogia e o ensino de ciências. Revista Ensino de Ciências e Humanidades. RECH, v. 1, n. 1, p. 336-358, 2018.

BENCKE, G. A. Biodiversidade. In: CHOMENKO, L.; BENCKE, G. A. (Orgs.). Nosso Pampa Desconhecido. Porto Alegre: Fundação Zoobotânica do Rio Grande do Sul, 2016. p. 61-75.

BENCKE, G. A.; CHOMENKO, L.; SANT'ANNA, D. M. O que é o Pampa? In: CHOMENKO, L.; BENCKE, G. A. (Orgs.). Nosso Pampa Desconhecido. Porto Alegre: Fundação Zoobotânica do Rio Grande do Sul, 2016. p. 17-27.

BEZERRA, R. G.; SUESS, R. C. A representação do bioma Cerrado em Livros didáticos de biologia do ensino médio. Holos, v.1, n.29, p. 233-242, 2013

BITTENCOURT, C. M. F. Foco, História, Produção e memória do livro didático. Rev. Educação e Pesquisa, v. 30, n. 3, 2004.

BOLDRINI, I. I. et al. Bioma pampa: diversidade florística e fisiômica. Porto Alegre: Pallotti, 2010.

BRACK, P. Crise da biodiversidade, ainda distante da economia. Ciência e Ambiente, n. 42, p. 147-162, 2011.

BRASIL. Recomendações para uma política pública de livros didáticos.

Brasília: Ministério da Educação, Secretaria de Educação Fundamental, 2001.

BRASIL. Monitoramento do Desmatamento nos Biomas Brasileiros por Satélite. 1. ed. Brasília, DF, 2011.

BRASIL. Resolução $n^{\circ}$ 2, de 15 de junho de 2012, que estabelece as Diretrizes Curriculares Nacionais para a Educação Ambiental. DOU n 116 , Seção 1 , págs. 70-71 de 18/06/2012.

BRASIL. Guia PNLD Campo 2016, Educação no Campo, Ensino Fundamental e Anos Iniciais. Ministério da Educação. Secretaria De Educação Continuada, Alfabetização, Diversidade e Inclusão, Brasília, DF, 2015a. 
BRASIL. Guia de livros didáticos: PNLD 2016: Ciências Humanas e da Natureza Coleção Integrada e Livros Regionais: ensino fundamental anos iniciais. Brasília, Ministério da Educação, Secretária de Educação Básica, 2015b.

BRASIL. Base Nacional Comum Curricular: Versão Final. Ministério de Educação. Brasília, DF, 2018.

BRESOLIN, A. J.; ZAKRZEVSKI, S. B. B. Percepção, comunicação e educação ambiental no processo de gestão participativa do Parque Estadual do Espigão Alto, RS. In: SANTOS, J. E.; ZANIN, E. M.; MOSCHINI, L. E. (Orgs.). Faces da Polissemia da Paisagem - Ecologia: Planejamento e Percepção. v. 4, São Carlos: RIMA, 2016.544 p.

CASTRO, L. R. B. O bioma Pampa como temática de investigação no ensino básico no município de Uruguaiana-RS. 2018. 180f. Dissertação (Mestrado em Educação em Ciências: Química da Vida e Saúde) - Universidade Federal de Santa Maria, Santa Maria/RS, 2018.

CHOMENKO, L. O pampa no atual modelo de desenvolvimento econômico. [Entrevista concedida a Revista do Instituto Humanistas Unisinos]. In: O pampa Silencioso, IHU on-line, ed.190, 2006.

CHOMENKO, L. Transformações estruturais no pampa. In: Wizniewsky, C. R. F.; FOLETO, E. M. (Orgs.). Olhares sobre o pampa: um território em disputa [recurso eletrônico]. Porto Alegre: Evangraf, 2017. p. 62-77.

CORREA, M. L. Origem do Descaso com o Bioma Pampa. 2008. $134 \mathrm{f}$. Monografia. (Especialização em Educação Ambiental). Centro Universitário La Salle. Canoas/RS. 2008.

COUTINHO, L. M. Biomas brasileiros. São Paulo: Oficina de Textos, 2016.

DELIZOICOV, N. C.; SLONGO, I. I. P. O ensino de Ciências nos anos iniciais do Ensino Fundamental: elementos para uma reflexão sobre a prática pedagógica. Série-Estudos, n. 32, p. 205-221, 2011.

FLAVIANO, S. L. L. A formação para o ensino de ciências nos currículos de pedagogia das instituições públicas de ensino superior do sudeste goiano. 2017. 11 1f. (Mestrado Programa de Pós-Graduação em Educação) Universidade Federal de Goiás, Catalão, GO, 2017.

GONÇALVES, J. P.; FARIA, A. H.; REIS, M. G. F. A. Olhares de professores homens de Educação Infantil: conquistas e preconceitos. Perspectiva, v. 34, n. 3, p. 988-1014, 2016. 
HORIKAWA, A.; JARDILINO, J. A formação de professores e o livro didático: avaliação controle dos saberes escolares. Revista Lusófona de Educação, v. 15, n.15, 2010.

IBGE. Instituto Brasileiro de Geografia e Estatística. Mapa de Biomas do Brasil: primeira aproximação. Rio de Janeiro: IBGE, 2004. Disponível em: <www.ibge.gov.br.>. Acesso em: 20 jan 2019.

INSTITUTO CHICO MENDES de Conservação da Biodiversidade - ICMBIO. Pampa. Disponível em: http://www.icmbio.gov.br/portal/unidadesdeconservacao/biomasbrasileiros/pampa. Acesso em: 18 jan 2019.

LONGHINI, M. D. O conhecimento do conteúdo científico e a formação do professor das séries iniciais do ensino fundamental. Investigações em Ensino de Ciências, v.13, n. 2, p. 241-253, 2008.

LOUSAN, N. E. P. Os desafios do professor de biologia na promoção de saúde na escola pública: Metodologias ativas de aprendizagem como caminho para a superação. 2014. 118f. Dissertação (Profissional em Educação nas Profissões de Saúde), Pontifícia Universidade Católica de São Paulo, Sorocaba, 2014.

LOURO, G. L. Mulheres na sala de aula. In: PRIORE. M. D.; PINSK. B. C. (Orgs.). História das mulheres no Brasil. São Paulo: Contexto, 2012. p. 441-481.

\section{MAZURANA, J.; DIAS, J. E.; LAUREANO, L. C. Povos e Comunidades}

Tradicionais do Pampa. Porto Alegre: Fundação Luterana de Diaconia, 2016.

MINAYO, M. C. S. Pesquisa Social: Teoria, método e criatividade. 18 ed. Petrópolis: Vozes, 2001.

MEDEIROS, A. B. et al. A Importância da educação ambiental na escola nas séries iniciais. Revista Faculdade Montes Belos, v. 4, n. 1, 2011.

MORAES, F. V. Os desafios e as possibilidades de ensinar ciências nos anos iniciais do ensino fundamental: uma investigação com professores. 2014. 204f. Tese (Programa de Pós-Graduação em Educação para a Ciência), Universidade Estadual Paulista (UNESP), Campus de Bauru, 2014.

OLIVEIRA, T. et al. Escola, conhecimento e formação de pessoas: considerações históricas. Políticas Educativas, v. 6, n. 2, p. 145-160, 2013.

OVERBECK, G. E. et al. Fisionomia dos campos. In: PILLAR, V. P. E LANGE, O. (Eds.). Os Campos do Sul. Porto Alegre: Rede Campos Sulinos - UFRGS, 2015. p. 33-44. 
PARIS, A. M. V. et al. O que os jovens gaúchos que residem na Mata Atlântica pensam sobre o Pampa? Perspectiva, v. 40, n. 152, p. 111-123, 2016.

PEDRINI, A.; COSTA, É. A.; GHILARDI, N. Percepção ambiental de crianças e pré-adolescentes em vulnerabilidade social para projetos de educação ambiental. Ciência e Educação. Bauru, v. 16, n. 1, p. 163-179, 2010.

PESSANO, E. F. C. et al. Percepções socioambientais de estudantes concluintes do ensino fundamental sobre o rio Uruguai. Ciências e ideias, $v$. 4, n. 2, p. 61-8, 2013.

PESSANO, E. F. C. et al. O Rio Uruguai Como Tema Para a Educação Ambiental no Ensino Fundamental. Revista Contexto \& Educação, v. 30, n. 96 , p. 29-63, 2015.

PRAIS, J. L. S.; ROSA, V. F. Nuvem de palavras e mapa conceitual: estratégias e recursos tecnológicos na prática pedagógica. Nuances: estudos sobre Educação, v. 28, n. 1, p. 201-219, 2017.

POZO, J. I.; CRESPO, M. A. G. A aprendizagem e o ensino de ciências: do conhecimento cotidiano ao conhecimento científicio. 5. ed. Porto Alegre: Artmed, 2009.

RIO GRANDE DO SUL. Referencial Curricular Gaúcho: Ciências da Natureza. Secretaria de Estado da Educação, Departamento Pedagógico. v. 1. Porto Alegre. 2018.

ROSA, C. W.; PEREZ, C. A. S.; DRUM, C. Ensino de física nas séries iniciais: concepções da prática docente. Investigações em Ensino de Ciências, v. 12, n. 3, p. 357-368, 2007.

SANTOS, K. G. F. Contribuição dos pecuaristas à sustentabilidade do Bioma Pampa no município de Quaraí, RS. 2015. 40f. Monografia (Especialização em Educação Ambiental), Universidade Federal de Santa Maria, Santa Maria/RS, 2015.

SANTOS, W. L. P. Educação científica na perspectiva de letramento como prática social: funções, princípios e desafios. Revista Brasileira de Educação, v. 12, n. 36, p. 474-550, 2007.

SANTOS, S.; SILVA, L. G. Mapeamento por imagens de sensoriamento remoto evidencia o bioma pampa brasileiro sob ameaça. Boletim de Geografia, v. 29, n. 2, p. 49-57, 2011.

SECRETARIA ESTADUAL DO MEIO AMBIENTE. Parque do Espinilho, 2007. 
SEMA. Secretaria do Meio Ambiente e Infraestrutura. Apoio à consulta pública. Criação do Monumento Natural Cerro do Jarau.

VIECHENESKI, J. P.; CARLETTO, M. Por que e para quê ensinar ciências para crianças. Revista Brasileira de Ensino de Ciências e Tecnologia, v. 6, n. 2 , 2013.

WordArt. Nuvem de palavras. Disponível em: <https://wordart.com/>. Acesso em: 20 jan. 2019.

Recebido em: 01 de setembro de 2020 Aprovado em: 24 de novembro de 2020 Publicado em: 15 de dezembro de 2020 (c) (i) (8) 